\title{
Salidas anticipadas y sucesión. La revocatoria de mandato al servicio de la competencia política
}

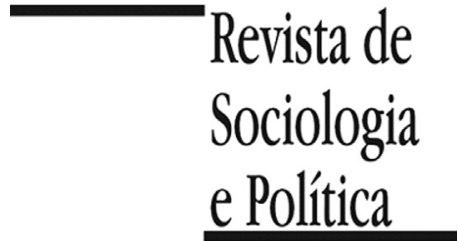

DOI 10.1590/1678-987320287401

\author{
Mario Daniel Serrafero' (iD), María Laura Eberhardt' iD \\ ${ }^{\mathrm{I} C O N I C E T}$, Ciudad de Buenos Aires, Argentina.
}

RESUMEN Introducción: La revocatoria de mandato es un mecanismo de control o accountability vertical, incorporado en varias constituciones latinoamericanas en mayor medida desde los años 90. Si el resultado del referéndum es el de revocar al representante, este cesa en el cargo y debe arbitrarse su reemplazo según la normativa. Materiales y Métodos: El supuesto que recorre el artículo es que el modo de reemplazo, electoral o no electoral, del mandatario es un factor relevante para definir el uso dado al mecanismo: como una herramienta de accountability social o como un instrumento de disputa político-electoral. A partir de la revisión de los casos de aplicación, se pretende dilucidar si es posible plantear una relación entre: el modo de sucesión de un mandatario revocado, la cantidad de solicitudes de revocatoria presentadas, la calidad de sus promotores y el tipo de uso dado al mecanismo. Para ello, se desarrolla un estudio exploratorio de los países latinoamericanos que incorporan la revocatoria en sus constituciones nacionales. Primero, se hace un análisis normativo de sus leyes fundamentales y de sus reglamentaciones, a fin de conocer el modo de sucesión previsto por cada Estado. Segundo, se efectúa un estudio de casos en profundidad para observar el desempeño del revocatorio en los hechos. Resultados: Tras el desarrollo de la investigación, se plantea la siguiente sugerencia: si el reemplazo se lleva a cabo por vía no electoral, las solicitudes de revocatoria suelen ser escasas y mayormente convocadas por los ciudadanos para librarse de malos gobernantes. En cambio, si la sucesión se define por elecciones, la revocatoria se usa con más frecuencia, y es mayormente convocada por actores políticos que pretenden acceder anticipadamente al cargo. Discusión: Dichos resultados ponen en cuestión la verdadera utilidad de un mecanismo que ha sido creado para favorecer el control ciudadano hacia los gobernantes, debido a que su diseño institucional puede habilitar un uso indeseado del mismo, atentando contra la gobernabilidad y la estabilidad institucional.

PALABRAS CLAVE: Revocatoria de mandato; Sucesión; Rendición de cuentas; Incentivo electoral; Manipulación política.

Recibido en el 26 de Abril de 2019. Aprobado en el 27 de Febrero de 2020. Acceptado en el 21 de Marzo de 2020.

\section{Introducción ${ }^{1}$}

${ }^{1}$ Agradecemos las sugerencias y comentarios de los dictaminadores anónimos de la Revista de Sociología e Política.
$\mathrm{L}$ a revocatoria de mandato es un mecanismo de control ciudadano que ha sido incorporado en varias constituciones latinoamericanas en mayor medida desde los años 90, en medio de un clima de crisis de la representación política. Habilita a la población a poner fin anticipado al mandato de un representante electo que ha perdido su confianza.

Una vez aprobada la revocación en el referendo, los mandatarios cesan inmediatamente en el cargo, abriéndose una etapa crucial vinculada con su modo de reemplazo: por elecciones, a través de un suplente o con selección interna. Este elemento, la modalidad de sucesión del mandatario revocado, se ha revelado a lo largo de este artículo como un factor relevante (variable independiente -VI), capaz de condicionar en forma anticipada otros aspectos centrales en el desempeño de este mecanismo. Tales aspectos son: a) la cantidad de solicitudes presentadas, las que pueden ser muchas, pocas o ninguna (variable dependiente 1 -VD1); la calidad de sus promotores, los que pueden ser ciudadanos o políticos (variable dependiente 2 -VD2); y, finalmente, el uso real dado al revocatorio, ya sea como instrumento de control ciudadano o como mecanismo de competencia electoral anticipada (variable dependiente 3 -VD3). 
${ }^{2}$ Sobre la crisis y metamorfosis de la representación política ver: Cavarozzi \& Abal Medina (2002), Eberhardt (2015), Manín (1997), Nino (1997), Porras (1996), entre otros. ${ }^{3}$ Sobre la incorporación de los mecanismos participativos ver: Altman (2005), Auer (2007), Barczak (2001), Eberhardt (2013b), Lijphart (2007), entre muchos otros.
El supuesto que emerge de este estudio normativo y empírico es que, cuando la sucesión del gobernante se concreta a través de un suplente o por selección interna (cerrada), la revocatoria se usa poco o nada, mayormente a manos de los ciudadanos y en razón de desbancar a un mal gobernante (control cívico). Por el contrario, cuando la sucesión consiste en el llamado a elecciones, la cantidad de solicitudes crece, generalmente a iniciativa de los actores políticos que hacen uso de este mecanismo como una vía de acceso anticipado al cargo (competencia político-electoral), desvirtuando no solo su espíritu de democracia directa, sino también amenazando la gobernabilidad y la estabilidad institucional.

Mucho se ha dicho ya respecto de la actual desafección democrática, al igual que de la crisis de credibilidad por la que atraviesan las principales instituciones del gobierno representativo en gran número de países occidentales ${ }^{2}$. También, se han estudiado ampliamente los mecanismos participativos incorporados en la mayoría de las constituciones en las últimas décadas (referéndums, iniciativas populares, audiencias públicas), destinados a apuntalar las democracias con más involucramiento cívico ${ }^{3}$. Sin embargo, la revocatoria de mandato ha quedado relegada de casi todos estos trabajos debido a su excepcionalidad: a nivel nacional, solo se encuentra en unas pocas constituciones y, mayormente, en países presidencialistas o semipresidencialistas, sobre todo en América Latina. Por otro lado, los pocos estudios específicos publicados sobre este mecanismo se han concentrado, sobre todo, en indagar en su diseño institucional y en los resultados de su aplicación, pero sin profundizar en las posibles causas de tales desempeños, positivos o negativos. Tampoco han logrado distinguir y clasificar la revocatoria según si es objeto de un uso cívico o político, esto es, en razón de sus objetivos de creación o al servicio de fines espurios.

Frente a tales vacíos existentes en la literatura académica, este artículo se enfoca, primero, en relevar los modos de sucesión o reemplazo previstos en los diseños normativos de la revocatoria de mandato -conocida en inglés como recall. Para ello, analiza las constituciones nacionales que incluyen este mecanismo en América Latina: Bolivia, Colombia, Ecuador, Perú y Venezuela. Cabe aclarar que Panamá también incluye la revocatoria de mandato y la revocatoria partidaria en su constitución nacional. Sin embargo, en su versión clásica, este mecanismo no ha sido usado en ese país. Segundo, estudia los casos de aplicación de este instrumento a cargos no presidenciales en tales países, para saber quiénes fueron sus promotores y cómo fue empleado. La meta es explorar si su uso se ha correspondido más con el ejercicio del control de los representantes en manos de los ciudadanos o con la competencia de poder por parte de los políticos. El supuesto que atraviesa este trabajo es que el reemplazo del revocado vía elecciones puede emparentarse más con lo segundo, al incentivar ambiciones de acceso anticipado al cargo y/o de venganza política.

A tal fin, el presente artículo se estructura en seis secciones, comenzando por esta "I. Introducción". La sección "II. Breve definición de la revocatoria de mandato", ofrece un análisis conceptual, desde diversas perspectivas teóricas, del significado y alcances de este mecanismo de control popular. En la sección "III. Salidas anticipadas y sucesión de los representantes", se incluye una explicación acerca de qué se entiende por tales conceptos, distinguiendo las dos fases que involucra la sucesión de los cargos electivos: la conclusión/interrupción del mandato del representante y la decisión sobre el reemplazo en cabeza del nuevo representante. Luego, la sección "IV. Mecanismos de sucesión en caso de revocatoria", continúa el análisis institucional. Específicamente, en dicho apartado se da cuenta del modo en el que las constituciones nacionales y las leyes reglamentarias de Venezuela, Bolivia, Ecuador, Perú y Colombia, estipulan el reemplazo del representante revocado (por suplente, selección interna o elecciones abiertas). En la sección "V. La revocatoria de mandato en los hechos: uso y resultados", se describen los casos empíricos de aplicación de 
la revocatoria en cada uno de estos países, haciendo hincapié en cómo fueron cubiertas las vacantes cuando el referéndum dio como resultado la separación del cargo de algún gobernante. En la sección "VI. Resultados", se presentan los productos obtenidos del estudio exploratorio sobre las constituciones y normativas reglamentarias de nivel nacional que incluyen la revocatoria en su articulado, así como de los casos empíricos de aplicación del mecanismo en los cinco países bajo estudio. Asimismo, se sintetizan e interpretan tales datos a la luz de la inquietud inicial de este trabajo: el modo en que los diferentes tipos de reemplazo del mandatario revocado pueden funcionar como estímulos diferenciales para los diversos impulsores de la revocatoria, condicionando en parte su frecuencia de uso y desempeño: como un instrumento para el control ciudadano o como una vía de disputa por el poder político. Finalmente, se incluye la sección "VII. Discusión”, en la que se ensaya una última reflexión general que interpreta los resultados prácticos obtenidos a la luz de la teoría de la representación política y la rendición de cuentas.

\section{Breve definición de la revocatoria de mandato}

La revocatoria de mandato constituye una herramienta de democracia directa, entendida esta última en términos de un conjunto de mecanismos que funcionan como medios de decisión política ejercidos por el sufragio directo y universal (Altman 2005, p.204). Dicho mecanismo revocatorio otorga a los ciudadanos la facultad de dejar sin efecto el mandato del titular de un cargo de elección popular, como resultado de un proceso de consulta, también popular (Zovatto 2008, p.260). Es una institución mediante la cual un número de electores impulsa la destitución de algún cargo ejecutivo y/o legislativo que dejó de gozar de la confianza de la ciudadanía (García Lema 1994, p.260).

La revocatoria conforma un instrumento de rendición de cuentas, o accountability, vertical, que surge desde la sociedad y se dirige al gobierno (O'Donnell 1998, p.13). Dentro de la dimensión vertical, es asimismo un mecanismo de $a c$ countability social, basado en las acciones de un amplio espectro de asociaciones, movimientos ciudadanos y actuaciones mediáticas, tendientes a monitorear el comportamiento de los gobernantes, a exponer y denunciar sus actos ilegales y a activar la operación de agencias horizontales de control (Smulovitz 2001, p.2). Como tal, abre una vía de defensa de los ciudadanos frente a gobernantes devenidos impopulares. Su principal función es la de habilitar una participación ciudadana "negativa" o de control, más que una función de expresión o gestión positiva de proyectos e iniciativas ciudadanas, ya que supone eliminar el contrato de representación erigido por el voto antes de que expire el período preestablecido (Eberhardt 2013a, p.15).

La misma fue incorporada junto con otros institutos de democracia directa en varias constituciones y legislaciones latinoamericanas, en mayor medida desde fines de los años 80 y durante los 90, en un contexto de crisis de la representación. El objetivo de estas reformas era abrir nuevos espacios institucionales para la participación y el control popular en los procesos de política pública, en un intento por recrear ciertos consensos sociales y políticos desgastados, en medio de un clima de pérdida de legitimidad de los mandatarios. Algunos Estados la adoptaron para revocar cargos a nivel nacional, alcanzando en ocasiones al mandato presidencial: Venezuela, Bolivia y Ecuador; lo que podría implicar una modificación en el funcionamiento del sistema presidencialista (Serrafero \& Eberhardt 2017, p.498). Pero fueron los cargos provinciales y locales los más alcanzados por este mecanismo.

Entre los aspectos negativos que pueden resultar del empleo de la revocatoria, Lissidini $(2007$, p.4) menciona lo que considera es uno de sus mayores peligros: poner en jaque al sistema representativo, especialmente si se abusa de 
él o se amenaza repetidamente con su utilización. Por otro lado, puede ser utilizado por un presidente como un mecanismo de ratificación popular para desautorizar procesos de juicio político o de control horizontal ejercido por los otros poderes (Serrafero \& Eberhardt 2017, p.507). Finalmente, como se presume en este artículo, la revocatoria puede funcionar como un mecanismo de destitución política anticipada de los gobernantes en manos de la oposición, especialmente cuando la designación de los reemplazantes se lleva a cabo por medio de nuevas elecciones. Esta ambición electoral anticipada, o revanchismo político, puede redundar en ingobernabilidad e inestabilidad de gobierno, contradiciendo los fines de su creación como herramienta de control ciudadano.

\section{Salidas anticipadas y sucesión de los representantes}

De las múltiples aristas que la revocatoria de mandato presenta para su estudio, esta investigación se concentra en indagar la relación posible entre el mecanismo de reemplazo del mandatario revocado (VI), la cantidad de solicitudes presentadas (VD1), la calidad de sus promotores (VD2), y el uso dado al mecanismo (VD3).

A tal fin, se toman como casos de estudio los países latinoamericanos que cuentan con revocatoria en sus constituciones nacionales: Venezuela, Bolivia, Ecuador, Perú y Colombia. Se exceptúa a Panamá debido a que no registra ejemplos de aplicación de este mecanismo por fuera de la revocatoria partidaria, ajena a este trabajo. El período abarcado va desde el año 1991, en el que la revocatoria, tal cual la conocemos hoy, se introduce por primera vez en una constitución nacional latinoamericana, la de Colombia y llega hasta 2015, año en que se producen las dos reformas reglamentarias más relevantes para este trabajo, en Perú y en Colombia.

En cuanto al tipo de cargos sujetos a revocatoria aquí abordados, se aclara que el presente estudio no incluye al del presidente, debido a que, en virtud de la relevancia suprema que dicho puesto tiene para el sistema presidencial, la dinámica política de una revocatoria del Ejecutivo nacional difiere en gran medida respecto de la de los restantes cargos aquí analizados (legislativos de todo nivel y ejecutivos subnacionales).

Para ampliar lo anterior, cabe aclarar que por dinámica política se entiende al proceso relacional de las fuerzas políticas en conflicto, dentro del cual gobierno, oposición y ciudadanía entran en una contienda para obtener el poder y ejercerlo (Pardo Martínez 2001, p.1). La magnitud de dicha contienda claramente difiere según el nivel de gobierno del que se trate. No es lo mismo la cantidad y diversidad de recursos (económicos, partidarios, carismáticos, mediáticos, sociales, internacionales, de trayectoria política, etc.) necesarios para disputar un cargo en un municipio, que en el nivel nacional de gobierno, y, más aún, si se trata de los cargos ejecutivos (unipersonales y supremos) en un sistema (hiper)presidencialista ${ }^{4}$. Es decir, el costo o los recursos requeridos para competir por una de las miles de intendencias que integran un Estado será muchas veces menor que el de disputar el único (y supremo) puesto disponible de presidente. Asimismo, los cargos ejecutivos locales resultan menos costosos y más sencillos de destituir que los nacionales. Por ejemplo, en el ámbito municipal es menor la cantidad de firmas a recolectar, el territorio a abarcar y el número de personas a persuadir en el referéndum; las acciones de los gobernantes son más visibles y factibles de ser controladas; etc.

Del otro lado, los recursos de poder que los mandatarios electos tienen a disposición (formal e informalmente) a la hora de defender sus puestos frente a un proceso revocatorio inminente también varían en alto grado según sea el

nivel de gobierno. Es de suponer que un presidente tendrá más y mejores recur-

"hiperpresidenciatis latinoamericano a la "aplicación deformada de régimen presidencial clásico, poderes del Parlamento hipertrofia de los poderes del presidente" (Duverger 1970, p.213). Se diferencia, por tanto, del modelo de los EEUU., caracterizado por el control mutuo y el equilibrio entre los poderes ejecutivo, legislativo y judicial (Serrafero 1998, pp.165; 171). 
sos de poder e influencia que un intendente a la hora de movilizar apoyos en su favor y revertir o interrumpir una destitución popular en su contra. Entre tales recursos defensivos superiores de un presidente, presumiblemente fuera del alcance de un intendente, podemos mencionar: la influencia sobre los órganos electorales y judiciales encargados de interpretar y aplicar (más o menos imparcialmente) las normas procedimentales de la revocatoria; su poder mediático, ya sea por contar con el uso de medios o cadenas del Estado para difundir sus argumentos, o por disponer de fondos publicitarios para premiar medios amigos y castigar a los enemigos; la posibilidad de contar con aliados de peso y fama mundial (presidentes, el papa, artistas, etc.), que lo ayuden a persuadir a la población para que voten a favor de su permanencia en el cargo; la capacidad de contar con fondos monetarios para distribuir discrecionalmente entre otros líderes políticos y sindicales, a fin de que convenzan a sus seguidores de apoyar su continuidad; entre muchos otros. Los casos de Hugo Chávez (2004) y de Nicolás Maduro (2016), en Venezuela, son buenos ejemplos.

Hecha la anterior aclaración, este artículo pretende recopilar evidencia de modo que nos permita sugerir una potencial relación entre: la modalidad de reemplazo del revocado, la cantidad de solicitudes presentadas, la calidad de sus promotores y el uso del mecanismo. Por ejemplo, se presume que la probabilidad de activación de la revocatoria será mayor cuando el reemplazo del revocado se decida por elecciones y no por otros medios (no electorales). En este caso, resulta más probable que sus promotores sean políticos interesados en competir anticipadamente por el cargo, que ciudadanos descontentos con el desempeño de algún mandatario; convirtiéndose la competencia electoral intra-élite (y no el control ciudadano) en el principal y más efectivo motor de dicho mecanismo.

Lo anterior implica suponer que el mecanismo de reemplazo de un mandatario revocado es un factor crucial, que puede influir en las características de su aplicación en cuanto a: cantidad de solicitudes presentadas (muchas, pocas, ninguna), calidad de sus promotores (ciudadanos o políticos) y tipo de uso dado a la revocatoria (destituir a un mandatario que ha perdido el apoyo popular o adelantar la competencia electoral en manos de antiguos y/o futuros contendientes políticos). Ahora bien, para hacer más viable esta relación, cabe comenzar por definir qué se entiende por interrupción del mandato y por sucesión accidentada de un representante.

III.1. Finalización del mandato

En los regímenes presidenciales, la sucesión de los cargos electivos tiene dos momentos -fácticos y jurídicos- diferentes, que no suelen distinguirse en la literatura específica. Esos son: 1- la conclusión/finalización del mandato del representante y 2- la decisión sobre el reemplazo por el nuevo representante. En cuanto al primer momento, 1- la conclusión/interrupción del mandato, esta puede producirse, en los hechos, de diversa manera. Lo normal y pautado según las constituciones y las legislaciones respectivas es que un mandato: 1- finalice cuando se ha vencido el tiempo correspondiente y 2- el sucesor sea el nuevo mandatario electo según las reglas electorales vigentes.

Sin embargo, no siempre el mandato concluye por expiración del tiempo previsto, sino que pueden ocurrir ciertos "accidentes" que truncan o ponen fin anticipado a la representación de un gobernante. Entre estos "accidentes" encontramos: la muerte, la renuncia, la destitución por impeachment o por algún mecanismo legislativo o mixto, la inhabilidad física o mental (Serrafero 2014, p.77) y, también, la revocatoria de mandato. Tales "accidentes" constituyen causas de un modo de interrupción del mandato que implica la salida anticipada del representante. Con excepción de la muerte, la mayoría de estas interrupciones se produce por acción de agentes institucionales o políticos. Cuando la 
interrupción del mandato corresponde a la figura del Ejecutivo nacional, se denomina "caída presidencial" (Hochstetler 2008, p.54).

Existen, por tanto, dos modos de conclusión/interrupción del mandato en términos constitucionales y legales: 1a) la conclusión normal, cuando el plazo del representante expira por acción del tiempo; y 1b) la interrupción accidentada, cuando el plazo se ve truncado por la acción de agentes institucionales (que pueden ser: el propio presidente, en caso de renuncia; el Congreso, en caso de impeachment y de declaración de inhabilidad física o mental; y los ciudadanos, en caso de revocatoria) o por la muerte.

Los procedimientos de finalización accidentada refieren a lo que Marsteintredet denomina "flexibilización de los regímenes presidencialistas", en tanto “atenúan los periodos fijos del presidencialismo y demuestran”, en contra de lo que suponía Linz, "que durante las crisis políticas los regímenes presidencialistas no son siempre rígidos" (Marsteintredet 2008, p.36). Como sostiene Serrafero, "una de las características más salientes de los presidencialismos latinoamericanos, a partir de la tercera ola de democratización, fue la superación de graves crisis políticas a través de mecanismos institucionales" (Serrafero 2018, p.404). Efectivamente, estas interrupciones accidentadas, canalizadas por vías institucionales y ya no por medio de la intervención militar, constituyen un nuevo y preocupante patrón de inestabilidad presidencial extendido en la región (Valenzuela 2008, p.16-17). En términos de Pérez Liñán, ello constituye "una paradoja creciente: la emergencia de democracias estables con gobiernos inestables” (Pérez Liñán 2008, p.106).

III.2. Reemplazo del revocado

El segundo momento es el de 2- la decisión sobre el reemplazo del representante que ha dejado de serlo. En la finalización normal, es decir, la conclusión del mandato, la decisión sobre quién es el titular reemplazante en el cargo se ha dado con anterioridad a dicha conclusión a través de elecciones, de modo que se produce una suerte de "sucesión automática". Cuando se concreta la conclusión por finalización del período, ya se ha solucionado previamente y se sabe de antemano quién sucederá al representante cuyo mandato ha expirado. Se da así una sucesión constitucional normal.

En la finalización accidentada, la decisión sobre el reemplazo del mandatario puede decidirse, al menos, de dos maneras: 2a) existe un sucesor predeterminado que asume luego de producido el accidente institucional (el suplente, el vice, el siguiente en la lista partidaria), y 2b) se procede a una selección del reemplazante que puede obedecer a distintos procedimientos entre un universo de candidatos restringido (por ejemplo, entre los miembros del Concejo Municipal) o ampliado. El acto electoral es el procedimiento de selección ampliado por excelencia.

¿Cómo se relacionan los dos momentos de las sucesiones? En las sucesiones constitucionales normales, 1- la conclusión/finalización y 2- el reemplazo van por carriles diferentes, dentro de una dinámica electoral regular. Antes de expirar el mandato, se realizan elecciones, que proveen la decisión sobre la sucesión del cargo (el reemplazante). El cumplimiento de las reglas de sucesión en condiciones de normalidad genera una dinámica que se reproduce.

Pero en sucesiones accidentadas, el modo de resolver el reemplazo puede incidir -o inducir- en la producción misma de la interrupción, de acuerdo a los intereses de los agentes promotores del accidente. Si el reemplazo está pautado automáticamente en un sucesor legal, ello significa que estará clausurada la posibilidad de que el reemplazante sea una persona distinta a quien está predeterminado por ley para cubrir la vacante. En cambio, si se trata de una 
selección amplia que conlleva una elección del reemplazante entre los ciudadanos habilitados, existe un mayor incentivo para que agentes institucionales o políticos provoquen la ocurrencia de un "accidente" institucional.

Llevadas estas reflexiones al caso concreto de la revocatoria de mandato, la interrupción por vía de este mecanismo podrá verse influida por el segundo momento, esto es, por el modo en que se resuelve el reemplazo. Si el mecanismo de cobertura de la vacante es mediante elecciones, es más probable que existan incentivos para promoverla entre todos los que creen tener chances de alcanzar el cargo. Es decir, la revocatoria se convierte en una herramienta política atractiva para dirimir las disputas de poder intra-élite. En cambio, si el mecanismo de cobertura del cargo es a través de un sucesor legal (por ejemplo, el suplente o el vice), existen menos incentivos electoral-partidarios para que se ponga en marcha el proceso de revocatoria (salvo por el propio sucesor legal). Es decir, en este caso, la revocatoria permanece cercana a su fin original de funcionar como un mecanismo de control social vertical de los ciudadanos hacia sus representantes.

\section{Mecanismos de sucesión en caso de revocatoria}

\section{IV.1. Venezuela}

${ }^{5}$ El Poder Público Municipal está conformado por los Municipios quienes constituyen la unidad política primaria de la organización nacional, gozan de personalidad jurídica y autonomía dentro de los límites de la Constitución y de la ley. La autonomía municipal comprende la elección de sus autoridades, la gestión de las materias de su competencia y la creación, recaudación e inversión de sus ingresos
En Venezuela, la revocatoria de mandato fue introducida por primera vez a nivel constitucional en 1999, con la nueva Ley Fundamental del presidente Hugo Chávez. Desde sus comienzos, este mecanismo alcanzó a todos los cargos electivos.

En este país, el reemplazo de los revocados no aparece incluido en la Resolución reglamentaria del mecanismo (Nº70906-2770, CNE, 2007), sino que se regula por otras normas específicas. Dejando de lado el cargo de presidente y vice (que no incluiremos en este análisis por las razones antes mencionadas), según la Ley N. 4.086 Sobre Elección y Remoción de los Gobernadores de Estado (1989), las faltas absolutas y temporales de los gobernadores serán suplidas de acuerdo con el procedimiento previsto en la correspondiente Constitución del estado. Mientras las constituciones de los estados no regulen la forma de suplir la falta absoluta de los gobernadores, se procede de la siguiente manera: si la falta absoluta se produjere en la segunda mitad del período (el caso de la revocatoria), la Asamblea Legislativa, dentro de los 30 días siguientes, procederá a designar por votación secreta un nuevo gobernador para el resto del período. Mientras se elige el nuevo gobernador, se encargará de la gobernación el secretario general del gobierno o el funcionario ejecutivo a cargo de los asuntos políticos. Esta ocupación interina del cargo deberá ser ratificada por la Asamblea Legislativa o la Comisión Delegada, dentro de las 48 horas siguientes.

Por su parte, la Ley 6.015 o Ley Orgánica del Poder Público Municipal ${ }^{5}$ (2010) estipula que, cuando la ausencia absoluta del alcalde se produjere transcurrida más de la mitad de su período (el caso de la revocatoria), el Concejo Municipal designará a uno de sus miembros para ejercer el cargo vacante por lo que resta del mandato municipal. El alcalde designado debe cumplir sus funciones de acuerdo al plan municipal de desarrollo aprobado para su gestión. Mientras se cumple la toma de posesión del nuevo alcalde, asume el presidente del Concejo Municipal. Aclárese que los cargos de alcalde y gobernador, no tienen vice.

Por último, las faltas absolutas producidas por la revocatoria del mandato de los funcionarios principales; ${ }^{6}$ cuando se trate de diputados de la Asamblea Nacional, legisladores a los consejos legislativos de los Estados, concejales de 
${ }^{6}$ Los funcionarios "principales" son los "titulares" del cargo, lo contrario de "suplentes".

IV.2. Bolivia

${ }^{7}$ La Asamblea Plurinacional es el órgano legislativo del Estado Plurinacional de Bolivia. Este país se organiza territorialmente en nueve departamentos, que a la vez se dividen en regiones. Estas regiones reúnen a 112 provincias, las que agrupan a 339 municipios y territorios indígenas. Cada uno de estos niveles de gobierno cuenta con una Asamblea legislativa y un órgano ejecutivo unipersonal.

\section{IV.3. Ecuador}

\footnotetext{
${ }^{8}$ En Ecuador, cada Región Autónoma elige por votación a su Consejo Regional y a su Gobernador Regional, que lo presidirá. Entre los consejeros regionales se elegirá un Vicegobernador. Dentro de las regiones, cada Provincia se gobierna por un Consejo Provincial integrado por un Prefecto, Alcaldes o Concejales en representación de los Cantones, y representantes de las Juntas Parroquiales. A su vez, las provincias se componen por dos o más cantones, gobernados cada uno por un Concejo Cantonal integrado por el Alcalde y los Concejales. Finalmente, cada Parroquia Rural tendrá una Junta Parroquial conformada por Vocales.
}

los concejos municipales y miembros de las juntas parroquiales; serán llenadas por sus respectivos suplentes, los cuales terminarían el periodo iniciado por los funcionarios revocados.

En ninguno de los casos aquí analizados (que excluyen al presidente) se prevén elecciones para reemplazar al mandatario revocado. De este modo, no se generan incentivos electorales altos para potenciales competidores.

En Bolivia, la revocatoria de mandato se introduce por primera vez en la nueva Constitución Política del Estado de 2009. Al igual que en Venezuela, alcanza a todos los cargos electivos. Este mecanismo se reglamentó por la Ley $\mathrm{N}^{\circ} 026$ del Régimen Electoral (LRE) de 2010, que aún se encuentra vigente (Eberhardt 2016, p.262).

Según la LRE, ante revocatoria del mandato de asambleístas plurinacionales, departamentales, regionales y concejales ${ }^{7}$, la Asamblea Legislativa Plurinacional (ALP) convocará a la elección de nuevos titulares y suplentes para la sustitución de los legisladores revocados hasta la finalización del periodo. Si pasados 15 días de la revocación la ALP no realiza la convocatoria, el Tribunal Supremo Electoral (TSE) lo hará inmediatamente.

Por otro lado, y tomando en cuenta las especificaciones de diversas normativas, si el revocado fuese un gobernador o un alcalde, no se convocará a elecciones para definir a su reemplazante. En el caso del gobernador, se elegirá internamente por los asambleístas departamentales; mientras que para alcaldes, la selección interna será realizada por los concejales (Recolección de firmas definirá qué autoridades van al revocatorio 2013).

Solo procederán elecciones cuando sean revocados cargos legislativos de cualquier nivel. Los mandatarios ejecutivos subnacionales son, en cambio, reemplazados por designación interna del cuerpo legislativo correspondiente.

En este país, la revocatoria de mandato se incluyó por primera vez en la Constitución Política del Ecuador de 1998. En esa oportunidad, los ciudadanos adquirieron el derecho a revocar el mandato otorgado a los alcaldes, prefectos ${ }^{8} \mathrm{y}$ diputados de su elección. La reforma constitucional de 2008 amplió su alcance a todas la autoridades de elección popular (Eberhardt 2018b, p.186).

Por su parte, la Constitución y el Código Orgánico de Organización Territorial, Autonomía y Descentralización (este último de 2010) definen los procedimientos a seguir para reemplazar a los mandatarios revocados. En ausencia de un gobernador, este es reemplazado por el vicegobernador, elegido por el Consejo Regional de entre sus miembros. Cuando se trata de la remoción de un prefecto, es nombrado un viceprefecto, elegido por votación popular. En los casos de remoción de un asambleísta (sea nacional o provincial), este es reemplazado por su suplente o alterno, elegido en una lista pluripersonal junto con su principal; al igual que en los casos que afectan a concejales o vocales miembros de las juntas parroquiales rurales. Si, por su parte, el revocado es el alcalde, asume el vicealcalde, que es un concejal elegido en la primera sesión del concejo cantonal o metropolitano para que cumpla esa función (Las revocatorias de mandatos tienen requisitos, 2015). Finalmente, ante la ausencia definitiva del presidente de la junta parroquial rural, este es reemplazado por su vicepresidente, que es el vocal que haya alcanzado la segunda más alta votación. 
En ninguno de estos casos se contempla el llamado a elecciones para completar el período, eliminando el incentivo electoral para los aspirantes tempranos al cargo.

IV.4. Perú

${ }^{9}$ En Perú, el accesitario es el congresista que reemplaza al titular cuando este no asiste a la sesión de comisión y cuando, habiendo asistido, se retira. Tiene derecho a voz y a voto. Es la persona que quedó en la lista de candidatos con opción preferente pero no llegó a ocupar un lugar como congresista.

\footnotetext{
${ }^{10}$ Los Regidores son representantes del Vecindario o de la Comunidad en Perú. Son elegidos por votación popular y, junto con el Alcalde, constituyen el Concejo Municipal Provincial y Distrital. Ejercen la función de Gobierno en las Municipalidades.
}

La Constitución Política del Perú de 1993, luego modificada por la Ley N ${ }^{\circ}$ 28.480 de 2005, concede a los ciudadanos el derecho a revocar autoridades electivas regionales y locales. La primera ley reglamentaria de la revocatoria de mandato es la $\mathrm{N}^{\circ} 26.300$, de 1994 , modificada luego por la Ley $\mathrm{N}^{\circ} 29.313$, de 2009. Esta normativa ha moldeado la extensa práctica de aplicación de la revocatoria acumulada en el Perú (1994-2015), y sus resultados han inspirado las últimas modificaciones realizadas en 2015.

A fin de sustituir a las autoridades revocadas y completar su mandato, la Ley 26.300 de 1994 preveía que el Jurado Nacional de Elecciones (JNE) acreditaría como reemplazante (salvo para los jueces de paz electos) a quien hubiere alcanzado el siguiente lugar en el número de votos de la misma lista. Tanto para el Concejo Municipal como para el Consejo de Coordinación Regional, únicamente se convocaría a nuevas elecciones para cubrir las vacantes si se confirmase la revocatoria de más de un tercio de sus miembros. Mientras no se eligiera a los reemplazantes en el cargo, asumirían los accesitarios? .

Esta posibilidad de convocar a nuevas elecciones ha sido interpretada como un incentivo para el uso de la revocatoria, pero no solo ni principalmente por la ciudadanía, sino, en mayor medida, por las fuerzas políticas que pudiesen albergar expectativas de acrecentar su presencia en el órgano colegiado. Ello debido a que, de alcanzarse dicho mínimo de destitución de un tercio de sus integrantes, se estarían adelantando las elecciones y conformando un Concejo o Consejo diferente por el tiempo remanente.

La Ley 29.313, de 2009, modificó a la 26.300. En adelante, el JNE acreditaría como reemplazante de la autoridad revocada (salvo respecto de los jueces de paz) para que completase el mandato: a) tratándose del presidente regional, al vicepresidente regional; b) tratándose del vicepresidente regional, a quién resulte elegido por el Consejo Regional entre los consejeros de la lista del revocado; c) tratándose simultáneamente del presidente regional y del vicepresidente regional, ídem anterior; d) tratándose de un consejero regional, al accesitario; e) tratándose del alcalde, al primer regidor hábil que sigue en la lista del revocado; y f) tratándose de un regidor ${ }^{10}$, al correspondiente suplente en la lista electoral del revocado. Se mantiene la convocatoria a elecciones en caso de revocarse a más de un tercio de los miembros del Concejo Municipal o del Consejo Regional.

En 2015, se realizó la segunda reforma a la Ley No 26.300. En virtud de los preocupantes resultados arrojados tras la aplicación de la normativa anterior, esta modificación estableció que en ningún caso habrá nuevas elecciones tras una revocatoria ( $;$ Se convoca a nuevas elecciones de proceder la revocatoria en un distrito? 2015). Las autoridades revocadas en los Concejos Municipales y Consejos Regionales serán reemplazadas por sus segundos inmediatos o por sus respectivos accesitarios. Esta modificación pretende evitar que los candidatos que perdieron los comicios inicien la revocatoria para llegar al poder antes de tiempo, tal como ocurrió entre 1994 y 2015, donde su uso excesivo con fines estratégico-electorales redundó en inestabilidad y dificultades en el ejercicio del gobierno. 


\section{IV.5. Colombia}

La Constitución Política de Colombia de 1991 incluye la facultad de todo ciudadano de revocar el mandato de los elegidos. Este derecho solo alcanza a gobernadores y alcaldes. Las leyes que regularon su ejercicio son: la $\mathrm{N}^{\circ} 131$ y la $\mathrm{N}^{\circ} 134$, ambas de 1994; la $\mathrm{N}^{\circ} 741$, de 2002, que reforma las anteriores; y la $\mathrm{N}^{\circ}$ 1.757, de 2015, también reformatoria (Eberhardt 2018a, p.459).

Respecto de lo que aquí nos convoca, la Ley $\mathrm{N}^{\circ} 131$ estipulaba que, revocado el mandato del gobernador o del alcalde, se convocaría a elecciones dentro de los dos meses siguientes. Mientras tanto, sería designado en calidad de encargado, por el presidente para el cargo de gobernador o por el gobernador para el cargo de alcalde, un ciudadano del mismo partido que el revocado. Esta modalidad sucesoria por elecciones alentaba expectativas electoralistas anticipadas por parte de los potenciales competidores.

La Ley $\mathrm{N}^{\circ} 134$ redujo a la mitad el plazo de dos meses concedido al llamado a elecciones y agregó que el sucesor debía cumplir el programa inscrito para la gestión gubernamental en el respectivo período. Esta y las posteriores reformas mantuvieron el llamado a elecciones para completar el período.

V.6. En síntesis

Como se muestra en el Cuadro 1, excluyendo la revocatoria presidencial, Bolivia y Colombia son los únicos países que mantienen hasta hoy el llamado a elecciones para cubrir algunas (el primero) o todas (el segundo) las vacantes producidas por revocatoria. De este modo, ofrecen incentivos electorales (medios en el caso de Bolivia y altos en el caso de Colombia) para que los

Cuadro 1 - Incentivos de acceso anticipado al poder

\begin{tabular}{|c|c|c|c|c|}
\hline \multirow[t]{3}{*}{ País } & \multirow[b]{3}{*}{$\begin{array}{c}\text { Tipo de } \\
\text { incentivo }\end{array}$} & \multicolumn{3}{|c|}{ Modo de reemplazo } \\
\hline & & $\begin{array}{c}\text { Sucesión por vice, suplente } \\
\text { o accesitario }\end{array}$ & $\begin{array}{l}\text { Selección interna entre un } \\
\text { grupo restringido }\end{array}$ & Elecciones abiertas alto \\
\hline & & $\begin{array}{l}\text { Incentivo de acceso } \\
\text { anticipado bajo }\end{array}$ & $\begin{array}{l}\text { Incentivo de acceso } \\
\text { anticipado medio }\end{array}$ & $\begin{array}{l}\text { Incentivo de acceso } \\
\text { anticipado alto }\end{array}$ \\
\hline Venezuela & & $\begin{array}{l}\text { Cargos legislativos de todos } \\
\text { los niveles (suplentes) }\end{array}$ & $\begin{array}{l}\text { Gobernador (Consejo legis- } \\
\text { lativo), alcalde (Concejo mu- } \\
\text { nicipal) }\end{array}$ & \\
\hline Bolivia & & & $\begin{array}{l}\text { Gobernador (asambleístas } \\
\text { departamentales), alcalde } \\
\text { (concejales) }\end{array}$ & $\begin{array}{c}\text { Cargos legislativos de todos los } \\
\text { niveles (convocada por la } \\
\text { Asamblea Nacional o por el } \\
\text { Tribunal Supremo Electoral) }\end{array}$ \\
\hline Ecuador & & $\begin{array}{c}\text { Cargos legislativos de todos } \\
\text { los niveles (suplente) Cargos } \\
\text { ejecutivos subnacionales } \\
\text { (vice) }\end{array}$ & & \\
\hline $\begin{array}{l}\text { Perú }(2009 \\
\text { a 2015) }\end{array}$ & & $\begin{array}{c}\text { Presidente regional } \\
\text { (vice), consejero regional } \\
\text { (accesitario), alcalde (el } \\
\text { regidor accesitario), regidor } \\
\text { (suplente) }\end{array}$ & $\begin{array}{c}\text { Vicepresidente regional o } \\
\text { presidente regional y vicepre- } \\
\text { sidente regional (el Consejo } \\
\text { Regional elige entre los } \\
\text { consejeros de la lista del } \\
\text { revocado) }\end{array}$ & $\begin{array}{c}\text { Cuando se revoque a más de } \\
1 / 3 \text { del Concejo Municipal o } \\
\text { del Consejo Regional (hasta } \\
\text { 2015) }\end{array}$ \\
\hline Colombia & & & & Gobernador y alcalde \\
\hline
\end{tabular}

Fuente: Elaborado por los autores. 
potenciales contendientes, ansiosos por llegar al poder, promuevan el uso del revocatorio con fines muy diferentes al del control popular. Perú eliminó esta vía en 2015, tras largos años de resultados ajenos a la accountability vertical y adversos a la gobernabilidad y a la estabilidad política. Por el contrario, Venezuela y Ecuador no cuentan, ni contaron, con este sistema de reemplazo de mandatarios revocados para los cargos en estudio.

\section{La revocatoria de mandato en los hechos: uso y resultados}

\section{V.1. Venezuela (2007)}

\author{
${ }^{11}$ Tras "la compleja y \\ traumática experiencia" de la \\ implementación fallida de la \\ revocatoria a nivel local en \\ Venezuela en el año 2003, \\ "solo en 2007 se volvió a \\ utilizar la revocatoria de \\ mandato en el país en el \\ ámbito local" (Kornblith 2014, \\ p.159).
}

\footnotetext{
${ }^{12}$ Ante la ausencia, en Venezuela, de la ley reglamentaria de la revocatoria prevista en la Constitución, la aplicación de este mecanismo se ha regido a partir de Resoluciones sucesivas aprobadas por el Consejo Nacional Electoral y de Sentencias emitidas por la Sala Constitucional y por la Sala Electoral del Tribunal Supremo de Justicia. Este órgano de Justicia, tomó decisiones y elaboró interpretaciones "de manera expedita y acomodaticia e incurriendo en graves distorsiones" (Kornblith 2014, p.123).
}

En el año 2007 ocurrió el segundo y (al menos hasta 2014) último ${ }^{11}$ intento de aplicación de la revocatoria en el ámbito local. El primero había sido en 2003, pero fue suspendido en este nivel por irregularidades procedimentales. Hacia marzo de 2007, de un total de 65 solicitudes presentadas, el CNE había aprobado la recolección de firmas para revocar el mandato a 4 gobernadores, 20 alcaldes y 4 diputados de asambleas regionales, todos electos en 2004.

$\mathrm{Al}$ cierre de ese período se aprobaron 167 solicitudes de revocatoria: 9 correspondían a gobernadores, 49 a legisladores de estados y 109 a alcaldes (28,35\% de las autoridades regionales y municipales electas en 2004). Muchas fueron iniciadas contra representantes de partidos que, en 2004, integraban la alianza gubernamental y, para 2007, se habían distanciado o rompieron con ella. De las 167 solicitudes aprobadas solo 10 superaron la etapa de recolección y verificación de firmas: 9 pedidos de revocatorias de alcaldes y 1 pedido contra una legisladora de estado, todos en distritos de poca población.

El 7 de octubre se sometieron a referendo revocatorio dichos mandatos, en forma simultánea e involucrando a 7 estados del país. Finalmente, se revocaron 5 autoridades: 3 alcaldes, 1 alcaldesa y 1 legisladora (CNE 2004). Por el contrario, no procedió la revocatoria contra 5 alcaldes (CNE anunció revocatoria de cuatro alcaldes y una legisladora regional 2007). La improcedencia se debió al incumplimiento de alguna de las condiciones requeridas por la norma.

La forma en la que fueron reemplazados los funcionarios revocados se rigió por lo establecido en la Sentencia de la Sala Constitucional del Tribunal Supremo de Justicia ${ }^{12}$, que señalaba que los legisladores serían sustituidos por los suplentes. En el caso de los alcaldes, correspondía a la Cámara Municipal el nombramiento de un sustituto. En ningún caso correspondía el llamado a elecciones.

En el caso venezolano, verificamos que, si bien lograron concretarse algunos procedimientos y revocaciones, solo el 5,99\% del total de las solicitudes aprobadas ese año llegó a instancia de votación, y solo el 2,99\% de dicho total terminó en revocatoria. La evaluación posterior acumuló críticas en contra de las dificultades que el diseño institucional del mecanismo oponía a su efectiva utilización.

En definitiva, la revocatoria de mandato en Venezuela se rigió durante largos años (desde 2003 en adelante) por resoluciones reglamentarias y decisiones ad hoc, que tendieron a dificultar su uso por parte de la población y la oposición política. Sus resultados fueron limitados y registraron una baja participación, siendo que la mayoría de los procesos no logró juntar los avales necesarios. Además, el hecho de que la sucesión de los revocados se resolviera, en estos cargos, por los suplentes del mismo partido o por designación de la Cámara Municipal, según correspondiera, excluyó de antemano cualquier incentivo electoral para potenciales contendientes anticipados al cargo. De tal modo, se eliminaba uno de los motores -inicuo y perverso- de activación de este mecanismo: el de la competencia velada por el poder político. Ello, sumado a que, en 2008, correspondía el llamado a nuevas elecciones en varios ámbitos, restó 
V.2. Bolivia (2012)

\footnotetext{
${ }^{13}$ La Ley de Régimen Electoral Transitoria, Ley 4021, aprobada por el Congreso Nacional, en 2009, creó siete Circunscripciones Especiales Indígena Originario Campesinas para facilitar la participación directa de los pueblos y naciones indígenas en la Asamblea Legislativa Plurinacional, en concordancia con la Constitución Política del Estado (Komadina, 2016:7)
}

V.3. Ecuador (1998-2017) impacto político e interés a los referéndums revocatorios de 2007, tanto por parte de la oposición, ocupada en los preparativos para los próximos comicios, como por parte de la ciudadanía, que pronto podría reemplazar a su gusto por sufragio electoral a los mandatarios cuestionados.

En Bolivia, la revocatoria de mandato pudo emplearse por primera vez, en forma plena, a mediados de 2012, luego de la aprobación por referendo de la Constitución de 2009 y la reglamentación de este mecanismo, en 2010 y 2012. Esta vez, era el turno de las autoridades asumidas en 2010. El reglamento de 2012 fijó los calendarios para la presentación de solicitudes de revocatoria a cargos nacionales y subnacionales.

Ese año se presentaron 124 solicitudes contra 216 autoridades elegidas: 168 concejales, 37 alcaldes, 5 asambleístas departamentales, 3 diputados uninominales, 1 gobernador, 1 ejecutivo seccional y 1 indígena de circunscripción especial $^{13}$. Entre ellos se encontraban el gobernador del Departamento de La Paz y el alcalde de La Paz.

Solo 79 solicitudes fueron aprobadas y pasaron a la etapa de recolección de firmas. Cada tribunal debía verificarlas, tras lo cual entregaría a la Asamblea Legislativa un informe sobre los funcionarios cuyos procesos revocatorios estaban habilitados y aquellos que habían sido rechazados. Acto seguido, ésta debía pronunciarse sobre la aprobación de una ley para convocar a los referendos. De revocarse a un gobernador o alcalde, se lo reemplazaría con selección interna entre los legisladores. Para legisladores de todo nivel se convocaría a elecciones.

De las 79 solicitudes inicialmente aprobadas, 48 fueron archivadas por no presentar las firmas correspondientes. De las restantes 31 solicitudes, solo 3 (contra alcaldes y concejales) lograron presentar el libro de avales. Sin embargo, de estas 3, ninguna superó el control de firmas debido a la falta de adhesiones.

La rigidez del calendario único para todos los procesos, unido a los altos requisitos impuestos por la normativa, impidieron llegar al referéndum y lograr las pretendidas revocaciones: si ninguna de las 124 solicitudes presentadas para los diferentes niveles de gobierno logró superar la barrera de firmas, es de sospechar que el piso establecido era excesivamente alto (Verdugo Silva 2014, p.151).

Cabe recordar que, en Bolivia, el reemplazo de los mandatarios revocados es por elección solo para los cargos legislativos de todos los niveles: senadores, diputados, asambleístas departamentales y concejales. En cambio, las vacantes de cargos ejecutivos subnacionales se cubren por designación del cuerpo legislativo correspondiente: los asambleístas departamentales para el gobernador y los concejales para el alcalde. Si bien existe un cierto incentivo electoral para destituir legisladores y aspirar a ocupar su lugar en forma anticipada, los puestos más deseados en un sistema presidencial por su carácter unipersonal (los ejecutivos), quedan fuera de estos incentivos.

De 1998 a 2008, el diseño institucional de la revocatoria estipulaba altos requisitos para su implementación, lo que redundó en una gran dificultad para reunir tanto los avales necesarios para llegar al referendo, como los votos para aprobar la destitución (Castellanos 2014, p.89). Como resultado, «durante este primer período las solicitudes para revocar una autoridad no se concretaron ni se 
${ }^{14}$ La Asociación de Municipalidades Ecuatorianas, creada en 1968, constituye una persona jurídica de derecho público y carácter permanente, con patrimonio propio y sede en la capital de la República cuyo principal objetivo es el de velar por el respeto y la garantía de los intereses municipales ejerciendo la representación de los Gobiernos Autónomos Descentralizados Municipales y Metropolitanos ante las instancias nacionales $\mathrm{e}$ internacionales.

V.4. Perú (1997-2013)

activó ningún proceso, lo que si ocurriría doce años más tarde» (Castellanos 2014, p.92). La reforma de la Constitución Nacional de 2008 y la reglamentación de 2009 y 2010 extendieron los alcances de este mecanismo a todos los cargos de elección popular y suavizaron las exigencias para su puesta en marcha.

Como consecuencia de tales reformas, en 2010, se presentaron las primeras solicitudes de revocatoria, las que pronto se multiplicaron. En total, se presentaron 730 pedidos de recolección de firmas, más a nivel local que nacional, y llegaron a votarse 78 referendos revocatorios (Tuesta Soldevilla 2014, p.17): 40 municipales, de los cuales 14 (el 37\%) fueron revocados; y 38 parroquiales, resultando revocados 6 (el 16\% de los mandatos) (Castellanos 2014, pp.99101). Si bien el dispositivo logró un nivel de uso positivo en relación con su desempeño anterior, aún así hubo una baja correspondencia entre el número de solicitudes presentadas y la cantidad de los mandatarios finalmente revocados, denotando una pérdida de respaldo del proceso a lo largo de sus diferentes etapas (Castellanos 2014, p.99).

Ante tal afluencia de solicitudes aprobadas, las autoridades electas no tardaron en apelar frente al Tribunal Contencioso Electoral, cuestionando los procesos de verificación de firmas (Castellanos 2014, p.95). A ello se sumó la acción de inconstitucionalidad presentada por el secretario general de la Asociación de Municipalidades Ecuatorianas ${ }^{14}$ (AME), en noviembre de 2010. En la misma, solicitaba suspender los procesos de revocatoria en curso y reformar la normativa, a la que consideraba contraria a la Constitución y de inadecuado desarrollo. Ambas demandas fueron concedidas.

En 2011 se aprobó un nuevo reglamento, que endureció los requisitos de aplicación de la revocatoria, revirtiendo los avances logrados tras la reforma constitucional. Ese año se presentaron 54 solicitudes, pero ninguna prosperó: la mayoría no fue aprobada por el CNE, por falta o fallas en la justificación de la solicitud o porque el promotor no había votado en la elección anterior. Lo mismo ocurrió en 2015, cuando se registraron 17 pedidos contra 15 alcaldes, 1 vicealcaldesa y 1 prefecto. Castellanos (2014, p.98) señala a estos nuevos requisitos como uno de los principales responsables de la disminución de las activaciones del mecanismo.

En lo que hace al interés específico de este artículo (los mecanismos de reemplazo de las autoridades revocadas), en el caso de Ecuador se adiciona la ausencia del incentivo electoral de reemplazo, ya que la sucesión se resuelve por suplentes y vicemandatarios. Un incentivo estratégico que, de estar presente, podría activar el motor político de la ambición de poder anticipado, bastante más efectivo que el motor popular de control vertical en su capacidad para poner en marcha y concretar revocatorias.

Este país se caracterizó por un uso recurrente y creciente de la revocatoria de mandato en el período 1997-2013, llegando a ser el mecanismo de participación ciudadana más usado en Perú, y el país latinoamericano donde más se lo ha usado. Entre los mencionados años, 5.304 autoridades pasaron por consulta de revocación y, para el referéndum de 2012, "el 54,5\% de los municipios ya habían tenido algún proceso de revocatoria” (Welp 2015, p.17).

En 16 años se llevaron a cabo 10 procesos de Consulta Popular de Revocatoria (CPR), mucho más a nivel distrital (municipal) que provincial o regional. Estos procesos abarcaron 4 períodos de gobierno; 11 provincias (incluida la capital) y 1.146 municipios (de un total de 1.645), de los cuáles la mayoría eran pequeños (menos de 5.000 electores) y el $90 \%$ eran rurales (de mayor preca- 
riedad y pobreza). Hubo 5.304 autoridades afectadas (1.124 alcaldes distritales y provinciales y 4.180 regidores), de las cuales 1.739 (el 32,7\%) resultaron revocadas: 303 alcaldes y 1.436 regidores.

La cantidad y frecuencia de solicitudes presentadas respondió, no solo al control ciudadano, sino también, y en mayor medida, a los deseos de revancha electoral, ambición y oportunismo de ex y/o futuros competidores al cargo. En términos generales, el alto número de autoridades revocadas en todo Perú, muchos de cuyos procesos fueron iniciados a solo un año de asumido el respectivo mandato, fue atribuido a una combinación de razones, entre las cuáles Welp (2015, p.2) destaca el diseño institucional del mecanismo (al menos hasta su reforma de 2015) y su estructura de incentivos para los actores políticos.

Tras las múltiples y frecuentes experiencias de aplicación relevadas en el país, se observó que, si bien "este mecanismo se ha convertido en una herramienta con respaldo ciudadano", "se utiliza para cobrar deudas electorales": "los candidatos perdedores utilizan este mecanismo en contra de los ganadores, y estos, increíblemente, resultan ser más que vulnerables ante una eventual revocación" (Vásquez Oruna 2014, pp.32-33). En concordancia con el supuesto central de este trabajo, tal número y frecuencia de casos, al igual que el carácter político-partidario de la mayoría de sus promotores, puede tener relación con el modo de reemplazo previsto para las autoridades revocadas. Como se vio más arriba, se trata del llamado a elecciones, que (hasta la reforma de 2015) se realiza cuando más de un tercio de los miembros del Concejo Municipal (cuerpo colegiado del que forma parte el alcalde) o del Consejo Regional resulta revocado.

Quizás, fue esta una de las razones para que las CPR municipales terminaran siendo solicitadas no solo para el alcalde o para algunos concejeros, sino para todo el Concejo, habilitando el llamado a elecciones para su reemplazo. Esto remite a "una serie de elementos -especialmente referidos al diseño institucional- que crean incentivos perversos, alentando la utilización frecuente de la revocatoria" (Welp \& Serdült 2014, pp.2-3). Penosamente, “estas prácticas (...) derivan en problemas de gobernabilidad y no resuelven los de falta de legitimidad democrática" (Ídem).

A nivel municipal, además de inestabilidad en el gobierno, el uso de este instrumento genera incertidumbre en el lapso de tiempo que media entre la destitución de un funcionario y la elección del reemplazante (especialmente cuando el alcalde no es revocado pero sí un tercio del Concejo); al igual que dificulta al alcalde la tarea de llevar adelante las políticas de gestión. Incluso, puede ocurrir que tras las nuevas elecciones el alcalde pierda su mayoría absoluta de regidores garantizada por el sistema electoral que lo invistió, y enfrente dificultades para mantener la gobernabilidad. Finalmente, cuando se revocan regidores pero el alcalde continúa en pie, suele ocurrir que varias (o incluso todas las) organizaciones que promovieron la revocatoria no se presenten a las elecciones, ya que su expectativa rondaba exclusivamente en torno de la figura del alcalde (Tuesta Soldevilla 2014, pp.26-27). El carácter revanchista de la práctica de la revocatoria en Perú, es destacada por Tuesta Soldevilla, cuando afirma que:

En el Perú, la revocatoria del mandato ha sido un mecanismo altamente corrosivo. Pensado para los gobiernos subnacionales, para ejercer control ciudadano, se ha vuelto una herramienta de intimidación y perjuicio contra los gobiernos locales (...). La revocatoria se convirtió así en el recurso de los que perdieron las elecciones y de antiguas autoridades, pero también un mecanismo de canalización de insatisfacción más allá de la gestión de la autoridad que se busca revocar. (Tuesta Soldevilla 2014, p.28)

Tan preocupantes efectos motivaron la reforma legislativa de 2015 que, no casualmente, entre sus principales medidas, eliminó las elecciones como mecanismo de reemplazo de las autoridades revocadas. Además, complejizó los 
requisitos para limitar la presentación de solicitudes. Habrá que esperar unos años para conocer su verdadero impacto.

V.5. Colombia (1994-2012)

En Colombia, desde la promulgación de las dos leyes reglamentarias de la revocatoria de mandato en 1994 y hasta el año 2012, se contabilizaron 134 intentos de revocatoria, pero ninguno de ellos prosperó.

Al igual que en Perú, la mayoría de las solicitudes fueron presentadas, no por organizaciones civiles o por la ciudadanía, "sino por ex alcaldes o gobernadores, candidatos derrotados o precandidatos electorales, que en defensa de intereses personalistas abusan del mecanismo en detrimento de la construcción de la democracia participativa" (Franco-Cuervo 2014, p.57). De hecho, los intentos por revocar mandatarios se incrementaban en los años preelectorales (Franco-Cuervo 2014, p.69). El incentivo electoral para el reemplazo de los gobernadores y alcaldes revocados fue de la mano con el gran interés demostrado por la elite política en el uso del revocatorio.

Respecto de los casos, entre 1996 y 2010 se votaron 37 referendos, pero ninguno logró la revocación y los mandatarios continuaron en sus cargos. De las revocatorias votadas ninguna prosperó porque no alcanzaron el mínimo de participación exigida. En 2011, luego de los comicios de autoridades locales, solo 1 solicitud aprobada fue a las urnas, pero no alcanzó el caudal de votos exigidos para desvincular al mandatario (RNEC 2013).

En 2013 se presentaron 33 solicitudes. La mayoría no superó la verificación del mínimo de firmas obligatorias y, de las que sí cumplimentaron este requisito, varias pasaron a revisión o apelación. Solo 7 llegaron a las urnas pero, siendo el voto optativo en ese país, no alcanzaron el mínimo de participación necesaria para validar el referendo, aunque la gran mayoría de los que votaron lo hizo a favor de la revocación. Así se describía en 2013 dicha situación:

Desde 1996 y hasta la fecha se han presentado ante la Registraduría Nacional del Estado Civil un total de 102 solicitudes para la revocatoria del mandato de diferentes mandatarios, de las cuales 52 no superaron la primera etapa de revisión de firmas, 6 superaron la revisión de firmas y están en proceso de resolver recursos, 5 se encuentran en revisión de firmas y otras 39 llegaron a las urnas, incluyendo la de Achí, Bolívar. 37 ya se votarony ninguna ha prosperado porque aunque el voto por el «sí» haya sido mayoritario, no se ha alcanzado el umbral mínimo necesario para revocar el mandato, que equivale al 55\% de la votación válida registrada. (El domingo 25 de agosto los ciudadanos de Achí, Bolívar, acudirán a las urnas para decidir si le revocan o no el mandato a su actual alcalde 2013)

Entre las críticas formuladas contra las flaquezas de la revocatoria destacan: reglamentación y requisitos excesivos, falta o inoperancia de garantías para los promotores, desconocimiento y falta de información de la ciudadanía, y desinterés frente a las instituciones y mecanismos participativos (Franco-Cuervo 2014, p.62).

Efectivamente, en los 8 años transcurridos desde su reglamentación en 1994 y hasta la reforma de 2002, de las 34 solicitudes presentadas 11 llegaron a votación, pero ninguna logró el apoyo necesario para destituir al funcionario. La reforma de 2002 pretendió allanar las dificultades, eliminando y suavizando requisitos. Consecuentemente, aumentó la cantidad de solicitudes en un $182 \%$ (96 iniciativas entre 2002 y 2012), pero solo 21 lograron superar la primera etapa del proceso y ninguna prosperó (Franco-Cuervo 2014, p.62). La ley 1.757 de 2015 también redujo los requisitos de aplicación y siguió manteniendo el reemplazo electoral de los mandatarios revocados. 
Para algunos funcionarios involucrados, el fracaso del mecanismo se debía a que dichos intentos habían sido promovidos y liderados por políticos opositores al mandatario de turno, así como a la falta de pertenencia de los habitantes con y para la ciudad (carencia de cultura cívica) (Franco-Cuervo 2014, p.67-68). Incluso, algunos promotores eran adversarios poco conocidos, que usaban ese mecanismo para salir a la luz con vistas a la próxima contienda: "un enfrentamiento entre políticos" (Franco-Cuervo 2014, p.68).

Por otro lado, el alto ausentismo verificado en la votación podría vincularse no solo con el carácter optativo del voto en Colombia, sino también con un desinterés lógico del ciudadano común respecto de una iniciativa que le resultaba extraña y ajena. Esa falta de adhesión es razonable en ausencia de una real insatisfacción ciudadana hacia el gobernante en cuestión. Si bien entre los sufragios emitidos el día de la consulta siempre triunfaba, y con amplia diferencia, el apoyo a la destitución, el bajo número de adhesiones totales que tal opción acumulaba podía estar dando cuenta de una distancia insalvable entre los intereses generales de la población y las aspiraciones de poder individual de los promotores políticos de la revocatoria. La situación de uso del mecanismo institucional, era descripta por Franco-Cuervo en los siguientes términos:

\begin{abstract}
Así las cosas, con los actuales (bajos) requisitos podría ocurrir que alcaldes o gobernadores elegidos democráticamente, pero sin amplio apoyo, solo puedan ejercer sus cargos durante un año, pues adversarios avezados en el juego político solo tendrán que esperar el segundo año para promover la revocatoria, argumentando la insatisfacción general de la ciudadanía, algo tan general y ambiguo que se vuelve simplemente un ejercicio de percepción de algunos sectores, y cuyo éxito dependería de la coyuntura, de los intereses en juego y del apoyo o no de los medios. (Franco-Cuervo 2014, p.73)
\end{abstract}

Si el fortalecimiento de la revocatoria de mandato como herramienta de $a c$ countability social en este país no se logra por el lado de seguir disminuyendo los requisitos de aplicación (ya bajos), se puede, en cambio, comenzar por eliminar el incentivo electoral de reemplazo de los revocados, al menos para evitar usos netamente partidario-electorales, ajenos al ejercicio del control ciudadano.

V.6. En síntesis

El Cuadro 2 ofrece un resumen comparado de los casos de empleo de la revocatoria de mandato en los cinco países analizados. Se pone en evidencia la distancia existente entre la cantidad de solicitudes presentadas y la cantidad de revocatorias finalmente aprobadas, pasando por la mención de cuántas solicitudes superaron los requisitos para su aprobación y cuántos referendos efectivamente se celebraron. Asimismo, se especifica qué tipos de promotores tuvieron las diversas iniciativas (ciudadanos y/o políticos) y si la normativa habilita el llamado a elecciones en caso de revocación. Puede observarse que, cuando existe sucesión por elección, los promotores de las iniciativas son mayormente actores políticos (Perú, Colombia), mientras que, cuando la sucesión se define por otro/s mecanismos/s no electorales, los iniciadores suelen ser ciudadanos (Ecuador). Bolivia constituye un caso intermedio porque conjuga ambas posibilidades.

\section{Resultados}

Hasta el momento, los estudios realizados sobre la revocatoria de mandato se han centrado en analizar sus objetivos de creación, los requisitos y pasos que deben seguirse para implementarla, y los resultados generales arrojados tras su aplicación. 
Cuadro 2 - La revocatoria en los hechos

\begin{tabular}{|c|c|c|c|c|c|c|c|}
\hline País /Año & $\begin{array}{c}\text { Sucesión por elección } \\
\text { (VI) }\end{array}$ & $\begin{array}{c}\text { Solicitudes } \\
\text { presentadas (VD1) }\end{array}$ & Promotor (VD2) & $\begin{array}{l}\text { Solicitudes } \\
\text { aprobadas }\end{array}$ & $\begin{array}{l}\text { Celebración del } \\
\text { referéndum }\end{array}$ & $\begin{array}{l}\text { Autoridades } \\
\text { revocadas }\end{array}$ & $\begin{array}{c}\% \text { de revocatorias } \\
\text { aprobadas en función } \\
\text { de las solicitudes } \\
\text { presentadas }\end{array}$ \\
\hline $\begin{array}{l}\text { Venezuela // } \\
2007\end{array}$ & No & $210^{\mathrm{I}}$ & $\begin{array}{l}\text { Muchas. Iniciadas contra representantes } \\
\text { de partidos que rompieron con la } \\
\text { alianza gubernamental. Iniciadas por } \\
\text { ciudadanos y por candidatos opositores. }\end{array}$ & 167 & 10 & 5 & $5 \times 100 / 210=2,38 \%$ \\
\hline Bolivia // 2012 & $\begin{array}{c}\text { Cargos legislativos de } \\
\text { todo nivel }\end{array}$ & $\begin{array}{l}124 \text { contra } 216 \\
\text { autoridades }\end{array}$ & $\begin{array}{l}\text { La mayoría fueron ciudadanos /vecinos } \\
\text { ajenos a la función pública. Las } \\
\text { restantes fueron promovidas a través de } \\
\text { organizaciones sociales }{ }^{I I}\end{array}$ & 79 & 0 & 0 & $0 \%$ \\
\hline Ecuador // 2010 & No & 730 & Ciudadanía & $597^{\mathrm{III}}$ & 78 & 20 & $20 \times 100 / 730=2,74 \%$ \\
\hline $\begin{array}{l}\text { Ecuador luego de } \\
\text { la reforma // } \\
2011 / 2015\end{array}$ & No & $54 / 17$ & Ciudadanía & $0 / 0$ & $0 / 0$ & $0 / 0$ & $0 \%$ \\
\hline $\begin{array}{l}\text { Perú // } \\
1997-2013\end{array}$ & $\begin{array}{l}\text { Hasta 2015: si se } \\
\text { revocase más de } 1 / 3 \text { del } \\
\text { Concejo Municipal o } \\
\text { Consejo Regional }\end{array}$ & $\begin{array}{l}5.800 \text { kits electorales } \\
\text { vendidos }^{\mathrm{IV}, \mathrm{V}}\end{array}$ & $\begin{array}{c}\text { En su mayoría candidatos perdedores y } \\
\text { antiguas autoridades (principalmente } \\
\text { las revocadas) }\end{array}$ & $\begin{array}{l}1.159 \text { (que } \\
\text { incluían a más } \\
\text { de un cargo) }\end{array}$ & 5.304 & 1.739 & $\begin{array}{c}1739 \times 100 / 5800= \\
29,98 \%\end{array}$ \\
\hline $\begin{array}{l}\text { Colombia // } \\
1994-2013\end{array}$ & $\begin{array}{l}\mathrm{Si}, \text { para todos los car- } \\
\text { gos sujetos a } \\
\text { revocatoria }\end{array}$ & 167 & $\begin{array}{l}\text { En su mayoría ex alcaldes o } \\
\text { gobernadores, candidatos } \\
\text { derrotados, opositores políticos o } \\
\text { precandidatos electorales }\end{array}$ & $102^{\mathrm{VI}}$ & 45 & 0 & $0 \%$ \\
\hline
\end{tabular}

Fuente: Elaborado por los autores.

${ }^{\text {I }}$ Dos siglos de revocatorio en Venezuela 2016.

II Tribunal recibe 19 pedidos de revocatoria de mandato 2013.

III Desde el 2010 seis alcaldes fueron destituidos mediante revocatorias en Ecuador 2018.

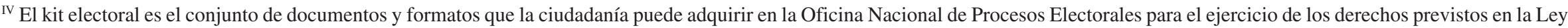

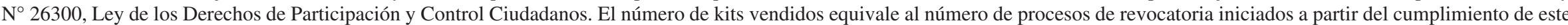
requisito inicial.

$\checkmark$ Tuesta Soldevilla, 2014, p.12.

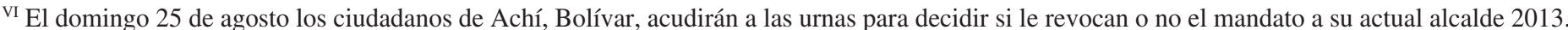


Si bien esta investigación es exploratoria y no busca confirmar o refutar una hipótesis inicial, pretendió reunir evidencia empírica adecuada, que permita sugerir una posible relación entre las siguientes cuatro variables: el mecanismo de reemplazo del mandatario revocado (VI), la cantidad de solicitudes presentadas (VD1), la calidad de los promotores (VD2), y el uso real del mecanismo (VD3).

Es decir, se trabajó sobre la presunción de que el modo dispuesto para reemplazar un mandatario revocado (sobre todo si es electoral) puede funcionar como un incentivo para la presentación de solicitudes de revocatoria (especialmente por los actores políticos), al tiempo que tiende a incidir en el uso dado al mismo (competencia político-electoral).

El Cuadro 3 sintetiza este modo de relación sugerido entre las cuatro variables. Los países en los que se combinan reemplazos electorales y no electorales para diferentes puestos serían casos mixtos o intermedios (como Bolivia). Se incluye una estimación general de la cantidad de solicitudes (muchas, pocas, ninguna) que sería razonable esperar para cada modo de reemplazo, así como de sus más asiduos promotores (actores políticos o ciudadanos) y del uso dado al mecanismo (control social o competencia político-electoral).

Cabe aclarar que este análisis debiera completarse con el estudio de los requisitos de aplicación de la revocatoria en cada país, los que pueden impactar en: la cantidad de solicitudes presentadas, el número de referendos votados, y la cantidad de revocatorias aprobadas. Esta cuestión excede los límites del presente artículo, quedando pendiente para futuras investigaciones y/o ampliaciones de este trabajo.

El relevamiento institucional y de casos de aplicación llevado a cabo sobre los cinco países en estudio arrojó datos que permiten inferir una relación posible entre: la modalidad electoral de reemplazo, mucha cantidad de solicitudes, su convocatoria por los contendientes del gobernante en cuestión, y un uso estratégico del mecanismo para canalizar la disputa de poder y acceder anticipadamente a los cargos. Los casos de Perú, hasta la reforma legislativa de 2015, y de Colombia son buenos ejemplos.

Cuadro 3 - Cantidad de solicitudes, promotor y uso del revocatorio según modo de reemplazo

\begin{tabular}{lccc}
\hline Modo de reemplazo (VI) & $\begin{array}{c}\text { Cantidad de solicitudes } \\
\text { esperables (VD1) }\end{array}$ & Calidad del promotor (VD2) & Uso del revocatorio (VD3) \\
\hline $\begin{array}{l}\text { Elecciones (incentivo de } \\
\text { acceso anticipado alto) }\end{array}$ & Muchas & $\begin{array}{c}\text { Mayormente actores } \\
\text { político-partidarios }\end{array}$ & $\begin{array}{c}\text { Mayormente por competencia } \\
\text { político-electoral }\end{array}$ \\
$\begin{array}{l}\text { Selección entre un grupo } \\
\text { restringido (incentivo de }\end{array}$ & Moderadas & $\begin{array}{c}\text { Actores político-partidarios con } \\
\text { influencia mayoritaria en el } \\
\text { acceso anticipado medio) }\end{array}$ & $\begin{array}{c}\text { órgano decisor } \\
\text { Competencia político-electoral }\end{array}$ \\
Sucesión por vice o suplente & Pocas & Ciudadanía & Control Social \\
\hline
\end{tabular}

(incentivo de acceso

anticipado bajo)

Seguidores del vice/suplente ${ }^{\mathrm{I}} \quad$ Competencia político-electoral

Fuente: Elaborado por los autores.

I Esta situación es bastante excepcional. Es más probable para los cargos ejecutivos de mayor relevancia (como gobernador) que para las bancas legislativas (menos visibles y relevantes). Puede esperarse cuando se suscita un enfrentamiento entre el titular y su vice/suplente, que incentiva a los seguidores del segundo a planificar la caída del titular con miras a su reemplazo definitivo. 
En efecto, los distintos casos abordados aportan una serie de evidencias y disparan reflexiones en ese sentido. Para comenzar, en Venezuela las solicitudes aprobadas fueron realmente pocas, y escasas las revocatorias de mandato concretadas. Ello puede asociarse, en parte, con la falta de incentivos electorales que estimularan un uso político -y por tanto mayor y más frecuente- del mecanismo. Efectivamente, los mandatarios revocados eran reemplazados por suplentes del mismo partido o por designación de las Cámaras, eliminando toda competencia electoral anticipada y reduciendo presumiblemente el interés de los opositores en el mecanismo.

Bolivia es un caso intermedio, ya que el reemplazo electoral solo alcanza a los puestos legislativos de todos los niveles. Siendo estos cargos menos atractivos para los candidatos que los puestos ejecutivos (unipersonales) y, a su vez, menos expuestos y asequibles al control individual (al integrar un órgano colectivo), dicha modalidad de reemplazo no implicó un incentivo electoral fuerte, que pudiese motivar en alto grado el inicio de procesos por parte de los contendientes políticos. Simultáneamente, el reemplazo de los cargos ejecutivos subnacionales vía selección interna de los respectivos órganos legislativos se correspondieron con iniciativas de revocatoria escasas, impulsadas mayormente por la ciudadanía, y que, además, terminaron en un rotundo fracaso (ni siquiera llegaron a votarse por incumplimiento de los requisitos).

En el caso de Ecuador, se observa que el reemplazo de los representantes sin elecciones se corresponde con un bajo uso de la revocatoria y con un empleo motorizado mayormente por los ciudadanos. A ello se suma que el endurecimiento de los requisitos en 2011 derivó en que ninguna de las solicitudes presentadas lograra siguiera llegar a instancia de votación.

En Perú, hasta 2015, ocurrió lo inverso. Inicialmente, se contemplaba el reemplazo electoral de los integrantes del órgano colectivo de gobierno local y regional cuando se hubiese revocado a más de un tercio de sus miembros. En estos primeros años, el uso del revocatorio fue muy frecuente y elevado, mayormente motorizado por miembros de la oposición con fines de venganza y/o de acceso anticipado a los cargos. Aquí, los resultados arrojados por la revocatoria fueron contraproducentes, dificultando la gobernabilidad y la estabilidad de gobierno. En 2015, frente a tales efectos indeseados, se aprobó una reforma legislativa que eliminó todo reemplazo electoral de los revocados.

Un caso diferente es el de Colombia. Allí subsiste el reemplazo electoral de todos los cargos revocables, que coincide con un alto uso del revocatorio, mayormente en manos de los opositores. Sin embargo, el voto optativo y la presunta falta de interés cívico en procesos sustentados en la pura especulación política han hecho naufragar todas las solicitudes aprobadas, ya sea por falta de presencia en las urnas o de sufragios favorables a la revocación.

Como se deja entrever luego de este trabajo, el uso del revocatorio en los distintos países no sólo, ni mayoritariamente, tiene que ver con el deseo legítimo de la ciudadanía de romper el contrato representativo con un mal mandatario, sino también con los incentivos que el reemplazo vía elecciones puede despertar en los competidores políticos del gobernante. Por lo general, los casos en los que el reemplazo se canaliza por suplentes o vía selección interna, las solicitudes registradas suelen ser escasas y mayormente impulsadas por los ciudadanos. Contrariamente, cuando la sucesión se dirime en términos electorales, puede haber un mayor y más frecuente uso del mecanismo, pero impulsado por políticos con ambiciones de poder o de venganza.

Por tanto, y aunque en adelante sea preciso contrastar empíricamente estas primeras afirmaciones, estamos en condiciones de sugerir que hasta el momento de la publicación de este artículo el uso de la revocatoria como un genuino 
${ }^{15}$ Para una versión ampliada de esta discusión ver: Eberhardt $(2019 ; 2020)$ mecanismo de control ciudadano resulta muy limitado en América Latina, tanto en la cantidad de iniciativas presentadas y/o aprobadas, como en el número de mandatarios finalmente revocados. Contrariamente, y en forma opuesta a los fines teóricos y normativos por los que fue creada, el uso perverso de la revocatoria por políticos interesados en acceder anticipadamente a los cargos, se muestra más asiduo y eficiente.

\section{Discusión}

La revocatoria es una forma de salida anticipada del cargo por parte de un funcionario electo. Este tipo de salida es "accidental", pues lo "normal" es la expiración del período predeterminado. Fue diseñada para permitir a los ciudadanos poner fin al mandato de un gobernante que ha perdido su confianza sin tener que esperar a que venza su período.

Al igual que la elección de los representantes, la destitución popular anticipada se canaliza a través del voto. Es, por tanto, un mecanismo democrático que habilita a los gobernados a romper el lazo de representación instaurado con un mandatario por medio del sufragio, cuando considera que éste ha incumplido repetida y/o gravemente con sus funciones o, lo que es lo mismo, cuando no se siente adecuadamente representado por este.

En tal sentido, la revocatoria de mandato constituye un mecanismo social de accountability, o rendición de cuentas vertical, iniciado desde abajo (los gobernados) y dirigido hacia arriba (los gobernantes). Permite a los ciudadanos controlar a sus representantes electos durante la mayor parte del mandato, sin verse obligados a esperar que este caduque para poder deshacerse de quienes hayan realizado un mal ejercicio del cargo.

A la luz de la teoría del mandato, la incorporación de este mecanismo de democracia directa constituye una novedad que viene a modificar las características y efectos de la representación política moderna. Efectivamente, el mandato representativo o libre, nacido de las revoluciones burguesas, se caracterizaba por el hecho de que el mandatario no representaba fragmentariamente a grupos o distritos aislados, sino a la Nación entera; motivo por el cual cada uno de los integrantes del cuerpo de representantes no estaba obligado a seguir las instrucciones de sus electores ${ }^{15}$. Ello determinaba la independencia del gobernante respecto de sus gobernados, con la consiguiente libertad para tomar sus decisiones y el carácter irrevocable de su designación.

La adopción de la revocatoria de mandato en algunas democracias indirectas contemporáneas implica un cambio de radical importancia respecto del modo en que pasa a percibirse y a ejercerse el lazo representativo. Esto resulta de la introducción de una instancia institucional de control y pedido de rendición de cuentas casi permanente de los gobernados hacia sus gobernantes, que incluso habilita a los primeros a hacer cumplir a los segundos, bajo pena de destitución, las expectativas generadas en torno de las plataformas políticas que ellos mismos presentaron con la finalidad de su elección.

En síntesis, la revocatoria ofrece a los mandantes una vía legal para que, en caso de flagrante y sostenida disconformidad con alguno/s de su/s gobernante/s, puedan recuperar el poder soberano delegado temporariamente a través del voto, destituir al funcionario en cuestión y proceder inmediatamente a reemplazarlo. De este modo, la representación política requiere una nueva cualidad, que resulta fundamental y necesaria: la capacidad de responder a los deseos y demandas ciudadanas (responsiveness). Esto es, la habilidad de gobernar responsablemente, con una constante atención y afán de dar satisfactoria respuesta a los intereses y demandas de sus representados. 
Ahora bien, llegados a este punto, cabe contrastar las prescripciones normativas o ideales establecidas por las teorías de la democracia, la representación, la accountability y el mandato antes referidos, con los resultados concretos recopilados tras el doble estudio exploratorio llevado a cabo en este trabajo.

En efecto, el análisis realizado de las constituciones y leyes reglamentarias de la revocatoria de mandato, combinado con el estudio en profundidad de sus casos de implementación empírica, han puesto en evidencia que este mecanismo puede ser usado no solo como un instrumento de control y castigo de los ciudadanos hacia sus gobernantes (lo que sería acorde con lo propuesto por las teorías invocadas). Por el contrario, en igual medida, o incluso con mayor frecuencia, está asimismo expuesto a un potencial empleo político-electoral por parte de los propios representantes, al servicio de sus ambiciones particulares. Este segundo empleo "perverso" desvirtúa y contradice abiertamente los loables objetivos teóricos y normativos esgrimidos en ocasión de su creación, justificación y puesta en marcha.

En lo que al interés central de este artículo respecta, se ha podido observar que la revocatoria de mandato no solo fue utilizada al servicio del control ciudadano (cuando el reemplazo del revocado se concretaba a través de un suplente o por selección interna cerrada), sino que también se advirtió un uso político electoral de este instituto (mayormente cuando el mecanismo de reemplazo era por elecciones).

En este segundo caso, son los opositores y/o competidores políticos, y no los ciudadanos "de a pie", los interesados en desalojar anticipadamente del cargo a sus titulares. De tal modo, la especulación de los actores deseosos de ocupar esas bancas convierte al mecanismo en una vía de disputa política, que nada tiene que ver con la herramienta de control inicialmente proyectada, en la que los ciudadanos genuinamente desilusionados promueven el desalojo de los representantes por su mal desempeño del mando.

Cabe pues, finalmente, sumar la reflexión de que el reemplazo electoral de un mandatario revocado puede resultar un arma de doble filo, capaz de convertir a un mecanismo de accountaiblity social en una peligrosa herramienta lista para ser usada en la lucha por el poder político, a través de la cual los candidatos derrotados y/o los políticos revocados pueden canalizar su venganza o su ambición electoral anticipada. Ello, con el concomitante costo de debilitar la gobernabilidad y atentar contra la estabilidad democrática. Sería este un paradójico caso en el que el remedio a la crisis de la representación política deviene una amenaza para la supervivencia democrática.

Mario Daniel Serrafero (mserrafero@gmail.com) es Doctor en Derecho Público por la UBA e investigador del CONICET.

María Laura Eberhardt (laura_rafaela@yahoo.com.ar) es Doctora en Ciencia Política por UNSAM e investigadora del CONICET.

\section{Referencias}

Altman, D. (2005) Democracia Directa en el continente americano: ¿autolegitimación gubernamental o censura ciudadana? Política y Gobierno, 12(2), pp.203-232.

Auer, A. (2007) Una mirada suiza sobre la democracia directa en América Latina. In: I Conferencia Internacional sobre Democracia Directa en América Latina, Research Centre on Direct Democracy-UNSAM-IDEA. Buenos Aires.

Barczak, M. (2001) Representation by Consultation? The Rise of Direct Democracy in Latin America. Latin American Politics and Society, 43(3), pp.37-59.

Castellanos, A.S. (2014) Ecuador: la transformación de las reglas del juego y sus consecuencias (1998-2013). In: Y. Welp \& U. Serdült (Comps.). La dosis hace el veneno. Análisis de la revocatoria del mandato en América Latina, Estados Unidos y Suiza. Quito: Consejo Nacional Electoral - Instituto de la Democracia, pp.83-110.

Cavarozzi, M. \& Abal Medina, J. M. (Comps.) (2002) El asedio a la política. Los partidos latinoamericanos en la era neoliberal. Rosario: Homo Sapiens. 
Duverger, M. (1970) Instituciones políticas y derecho constitucional. Barcelona: Ariel.

Eberhardt, M. L. (2013a) Crisis de la representación en las democracias presidencialistas latinoamericanas ¿La revocatoria de mandato como opción? Revista Elecciones, 12(13), pp.13-51.

Eberhardt, M. L. (2013b) Siga participando... dedicado a los ciudadanos de las democracias reales. Los mecanismos de participación y control societal en la Ciudad de Buenos Aires. Buenos Aires: Prometeo.

Eberhardt, M. L. (2015) Democracias representativas en crisis. Democracia participativa y mecanismos de participación ciudadana como opción. Araucaria. Revista Iberoamericana de Filosofía, Política y Humanidades, 17(33), pp.83-106.

Eberhardt, M. L. (2016) La Revocatoria de Mandato en Bolivia. Su diseño institucional. El caso Evo Morales (2008). Acciones e Investigaciones Sociales, s/v(36), pp.253-278.

Eberhardt, M. L. (2018a) La Revocatoria de Mandato en Colombia: diseño institucional y resultados de su aplicación. Revista de Derecho Político, s/v(103), pp.454-483.

Eberhardt, M. L. (2018b) La Revocatoria de Mandato en Ecuador: avances y retrocesos. Revista de Ciências Humanas, 17(1), pp.182-199.

Eberhardt, M. L. (2019) El mandato y su revocación desde la relación jurídico-política entre electores y elegidos. Revista General de Derecho Constitucional, s/v(29).

Eberhardt, M. L. (2020) La Revocatoria de Mandato en las democracias representativas contemporáneas: ¿hacia un nuevo tipo de relación jurídico-política entre electores y elegidos? Revista Argentina de Derecho Electoral, s/v(2). Disponible en: $<$ https://ar.ijeditores.com/mobile/pop.php?option=publicacion\&idpublicacion=401\&idedicion=3980>. Acceso en: 16 de nov. 2020.

Franco-Cuervo, A. B. (2014) Colombia: instituciones, líderes políticos y abstención electoral (1991-2013). In: Y. Welp \& U. Serdült (Comps.). La dosis hace el veneno. Análisis de la revocatoria del mandato en América Latina, Estados Unidos y Suiza. Quito: Consejo Nacional Electoral - Instituto de la Democracia, pp.57-82.

García Lema, A. (1994) La reforma por dentro. La difícil construcción del consenso constitucional. Buenos Aires: Planeta.

Hochstetler, K. (2008) Repensando el presidencialismo: desafíos y caídas presidenciales en el Cono Sur. América Latina Hoy, 49(s/n), pp.51-72.

Komadina, J. (2016) Paradojas de la representación política en Bolivia. L’Âge d'or [online], s/v(9), pp. 1-15. DOI: 10.4000/agedor. 1156

Kornblith, M. (2014) Revocatoria del mandato presidencial en Venezuela: definición y puesta en práctica. In: A. Lissidini, Y. Welp \& D. Zovatto (Comps.). Democracias en movimiento. Mecanismos de democracia Directa y participativa en América. México, DF: Universidad Nacional Autónoma de México, pp.131-166.

Lijphart, A. (2007) Democracia Directa en América Latina: entre la Participación y la Delegación. Documento de Trabajo, $N^{\circ}$ 17, Serie de Documentos de Trabajo, Buenos Aires: Escuela de Política y Gobierno - UNSAM.

Lissidini, A. (2007) Democracia Directa en América Latina: entre la Participación y la Delegación. Serie de Documentos de Trabajo, Documento de Trabajo, $n^{\circ} 17$. Buenos Aires: Escuela de Política y Gobierno - UNSAM, pp.1-45.

Manín, B. (1997) Los principios del gobierno representativo. Madrid: Alianza.

Marsteintredet, L. (2008) Las consecuencias sobre el régimen de las interrupciones presidenciales en América Latina. América Latina Hoy, 49(s/n), pp.31-50.

Nino, C. (1997) La constitución de la Democracia Deliberativa. Barcelona: Gedisa.

O’Donnell, G. (1998) Accountability horizontal: la institucionalización legal de la desconfianza política. Ágora, cuaderno de estudios políticos, s/v(8), pp.5-34.

Pardo Martínez, O. (2001) Poder y oposición: la dinámica política. Reflexión Política, 3(6), pp.1-13.

Pérez Liñán, A. (2008) Instituciones, coaliciones callejeras e inestabilidad política: perspectivas teóricas sobre las crisis presidenciales. América Latina Hoy, 49(s/n), pp.105-126.

Porras, A. (1996) El debate sobre la crisis de la representación política. Madrid: Tecnos.

Serrafero, M. D. (1998) Presidencialismo y parlamentarismo en América Latina: un debate abierto. Revista Mexicana de Sociología, 4(1), pp.165-186.

Serrafero, M. D. (2014) Flexibilización del presidencialismo en América Latina: un fenómeno nuevo? Revista de Estudios Políticos, s/v(63), pp.67-99.

Serrafero, M. D. (2018) Siete cuestiones en torno de la teoría de las caídas presidenciales. Política y Gobierno, 25(2), pp.403-440.

Serrafero, M. D. \& Eberhardt, M. L. (2017) Presidencialismo y Revocatoria de mandato presidencial en América Latina. Política y Sociedad, 2(54), pp.497-519.

Smulovitz, C. (2001) Judicialización y Accountability Social en Argentina. In: Latin American Studies Association XXII International Conference. Washington, D. C.

Tuesta Soldevilla, F. (2014) Perú: entre la participación y la gobernabilidad local (1997-2013). In: Y. Welp \& U. Serdült (Comps.). La dosis hace el veneno. Análisis de la revocatoria del mandato en América Latina, Estados Unidos y Suiza. Quito: Consejo Nacional Electoral - Instituto de la Democracia, pp.7-30.

Valenzuela, A. (2008) Presidencias latinoamericanas interrumpidas. América Latina Hoy, 49(s/n), pp.15-30.

Vásquez Oruna, E. M. (2014) Cuando los vientos revocadores azotaron Lima. In: Y. Welp \& U. Serdült (Comps.). La dosis hace el veneno. Análisis de la revocatoria del mandato en América Latina, Estados Unidos y Suiza. Quito: Consejo Nacional Electoral - Instituto de la Democracia, pp.31-56. 
Verdugo Silva, J. T. (2014) Bolivia: entre la expectativa de uso y los intentos fallidos de activación. In: Y. Welp \& U. Serdült (Comps.). La dosis hace el veneno. Análisis de la revocatoria del mandato en América Latina, Estados Unidos y Suiza. Quito: Consejo Nacional Electoral - Instituto de la Democracia, pp.135-158.

Welp, Y. (2015) Recall referendums in Peruvian municipalities: a political weapon for bad losers or an instrument of accountability? Democratization, 23(7), pp.1162-1179. DOI: 10.1080/13510347.2015.1060222

Welp, Y. \& Serdült, U. (2014) La revocatoria de mandato: propuesta de análisis. In: Y. Welp \& U. Serdült (Comps.). La dosis hace el veneno. Análisis de la revocatoria del mandato en América Latina, Estados Unidos y Suiza. Quito: Consejo Nacional Electoral - Instituto de la Democracia, pp.1-6.

Zovatto, D. (2008) Las instituciones de la democracia directa a nivel nacional en América Latina. Balance comparado: 1978-2007. In: A. Lissidini, Y. Welp \& D. Zovatto. (Coords.) Democracia Directa en Latinoamérica. Buenos Aires: Prometeo.

\section{Otras fuentes}

CNE (2004) Elecciones Regionales 10/2004. Disponible en: http://www.cne.gob.ve/regionales2004. Acceso el: 9.Sep.2018. RNEC (2013) Ya se pueden solicitar revocatorias de mandato. Nuestra huella, Bogotá.

\section{Artículos y diarios}

CNE anunció revocatoria de cuatro alcaldes y una legisladora regional. 2007. Consejo Nacional Electoral. Caracas, 9. Oct. Disponible en: <https://www.cne.gob.ve/web/sala_prensa/noticia_detallada.php?id=579>. Acceso en: 09 de Sep. 2018.

Desde el 2010 seis alcaldes fueron destituidos mediante revocatorias en Ecuador. 2018. El Universo. 30. Jun. Disponible en: $<$ https://www.eluniverso.com/noticias/2018/06/30/nota/6835490/2010-seis-alcaldes-fueron-destituidos-mediante-revo catorias>. Acceso en: 16 de Nov. 2020.

Dos siglos de revocatorio en Venezuela. 2016. Observatorio Electoral Venezolano. Caracas, 1. Nov. Disponible en: <http://www.oevenezolano.org/2016/11/01/dos-siglos-de-revocatorio-en-venezuela>. Acceso en: 16 de Nov. 2020.

El domingo 25 de agosto los ciudadanos de Achí, Bolívar, acudirán a las urnas para decidir si le revocan o no el mandato a su actual alcalde. 2013. Comunicado de Prensa $N^{\circ}$ 478. Bogotá. Disponible en: <http://www.registraduria.gov.co/El-domingo-25-de-agosto-los.html>. Acceso en: 16 de Nov. 2020.

Las revocatorias de mandatos tienen requisitos. 2015. El Telégrafo. Quito, 22. Ene. Disponible en: $<$ http://www.eltelegrafo.com.ec/noticias/informacion-general/1/las-revocatorias-de-mandato-tienen-requisitos-infografia>. Acceso en: 16 de Nov. 2020.

Recolección de firmas definirá qué autoridades van al revocatorio. 2013. Opinion.com.bo. Cochabamba, 9. Abr. Disponible en: <http://www.opinion.com.bo/opinion/articulos/2013/0409/noticias.php?id=91309>. Acceso en: 16 de Nov. 2020.

¿Se convoca a nuevas elecciones de proceder la revocatoria en un distrito? Elecciones en Perú. Lima. Disponible en: $<\mathrm{http}: / / \mathrm{www}$.eleccionesenperu.com/informacion-electoral-nuevas-elecciones-por-autoridades-revocadas-75.html>. Acceso en: 4 de Dic. 2018.

Tribunal recibe 19 pedidos de revocatoria de mandato. 2013. Bolivia Decide. 3. Dic. Disponible en: <http://boliviadecide.blogspot.com.ar/2013/01/tribunal-recibe-19-pedidos-de.html>. Acceso en: 16 de Nov. 2020. 


\section{Early departures and succession. Recall at the service of political competition}

ABSTRACT Introduction: The recall is a vertical accountability mechanism incorporated in several Latin American constitutions to a greater extent since the 90s. If the result of the referendum is to revoke the representative, he ceases in office and must be arbitrated to replace it according to the regulations. Materials and methods: The assumption that runs through the article is that the mode, electoral or non-electoral, of replacement of the representatives a relevant factor to define the use given to the mechanism: as a tool of societal accountability or as an instrument of electoral political dispute. From the review of the application cases, the aim is to clarify whether it is possible to establish a relationship between: the mode of succession of a revoked agent, the number of requests for recall submitted, the quality of their promoters and the type of use given to the mechanism. For this, an exploratory study of the Latin American countries that incorporate the recall in their national Constitutions is developed. First, a normative analysis of its fundamental laws and regulations is made, in order to know the mode way of succession provided by each State. Second, an in-depth case study is carried out to observe the performance of the recall in the facts. Results: After the development of the investigation, the following suggestion is made: if the replacement is carried out by non-electoral means, the cases of recall are usually scarce and mostly called by citizens to get rid of bad rulers. On the other hand, if the succession is defined by elections, the recall is used more frequently, and mostly by political actors who intend to gain early access to office. Discussion: These results call into question the true usefulness of a mechanism that has been created to favor citizen control the rulers, because its institutional design can enable its unwanted use, undermining governability and institutional stability.

KEYWORDS: Recall; Succession; Accountability; Electoral incentive; Political manipulation.

This is an Open Access article distributed under the terms of the Creative Commons Attribution Non-Commercial License which permits unrestricted non-commercial use, distribution, and reproduction in any medium provided the original work is properly cited.

A produção desse manuscrito foi viabilizada através do patrocínio fornecido pelo Centro Universitário Internacional Uninter à Revista de Sociologia e Política. 